\title{
Quantitative method for determining the solution error of the inverse problem in the electrometry of oil and gas wells
}

\author{
Mykyta Myrontsov ${ }^{1, *}$, Oleksiy Karpenko ${ }^{2}$, and Volodymyr Horbulin ${ }^{1}$ \\ ${ }^{1}$ Institute of telecommunications and global information space of NAS of Ukraine, Kyiv, Ukraine \\ ${ }^{2}$ Taras Shevchenko National University of Kyiv, Kyiv, Ukraine
}

\begin{abstract}
Determining the quantitative degree of connection between logging error and the corresponding error of oil and gas wells electrometry inverse problem solving is considered. A quantitative method to determine the magnitude of the error of solving the inverse problem depending on the magnitude of the logging error for a given model of a single layer or section as a whole is described. Examples of determining the error of the inverse problem for real well materials, taking into account the actual measurement error, are given. A method for determining the characteristics of the spatial resolution of electrometry methods is described. Examples of its use for low-frequency induction logging equipment are given. The proposed methods allow to determine the areas of equivalent solutions and the areas of existence of stable / unstable solutions of the inverse electrometry problem.
\end{abstract}

\section{Introduction}

The geoelectric parameters definition problem of the section helps to answer two questions [1]:

- Where is the useful fluid?

- How many are there?

Determining these geoelectric parameters requires solving an inverse mathematical problem that links the data of direct measurement of some apparent conductivity (AC) or apparent resistivity (AR) values around the well space with unknown values of these parameters of the model of the studied section. The main method of solving such problems is numerical. But almost any numerical solution involves error. So the final result of solving such a problem will not be a numeric value (or a vector in vector space), but some area of possible values. However, all elements in this area will have the same opportunity to be the solution of the problem. This means that they are equivalent. The size of the area of equivalent solutions that accord the same initial conditions determines the spatial resolution of the solution. In general, it allows us to identify areas of sustainable solutions. And accordingly, identify areas where there are no stable solutions.

\section{Analysis of previous publications}

There are many reasons for the problem of defining the boundaries of productive intervals in vertical and inclined vertical oil and gas wells. One of the main reasons is the insufficient (for many of the conditions inherent in the Dnipro-Donetsk depth) vertical resolution of geophysical well research (GWR) complexes used in practice. The use unfocused laterolog tools (BKZ), where most sondes are not symmetrical is one of the factors of such a problem. To illustrate it we can cite the well-known problem of determining the position of water-oil contact, the solution of which is devoted to many studies.

The error in determining the boundaries of productive intervals leads to an error in determining the daily flow rate of useful fluid (due to inaccurate determination of perforation) and, accordingly, is a factor in the error of the initial conditions of further technical operation of the well as an anthropogenic loading on the environment.

The work is part of a study of the possibilities of improving the efficiency of solving inverse problems of well electrometry [2-4].

In general, many program-methodological and analytical methods have been developed to analyze the impact of violation of technical requirements for the exploitation of wells on the ecosystems of hydrocarbon production areas [5-13].

The problem of the impact of the oil and gas wells exploitations on the ecological state of the geosphere is more than topical [14-17].

Applied tasks even include the study of the effects of hydrocarbon extraction on the development of regional tourism. This is more than relevant because the Carpathian region is potentially oil and gas and is one of the centers of tourism in Ukraine [18-23].

The environmental impact of oil and gas well operation is also similar to the environmental impact of fuel combustion in boilers [24-27].

In addition, the inevitable use of radioactive methods together with electrometric methods in GWR requires solving the problem of the impact of such methods on different components of the geosphere [28-31].

* Corresponding author: myrontsov@ukr.net 
The combination of all these approaches makes it possible to use already developed decision support systems [32-40].

It should also be noted that to increase the efficiency of numerical calculation in recent decades has become widely used method of physical simplification. This method is widely used in solving modeling problems of engineering problems and is to simplify the equations of mathematical physics by introducing simplifications that take into account the physical content of processes [4151].

\section{The solution error of the inverse problem and the spatial resolution of the inverse problem}

\subsection{Error solving the inverse problem}

The main error that occurs in the problems of electrometry is a significant measurement error (sometimes the allowable error is an error of $20-40 \%$ ).

In addition, there may be other possibilities of error. The occurrence of an error in solving the inverse problem can be due, for example, to the following reasons:

1) its mathematical description is inaccurate, in particular inadequately or inaccurately described the model itself or its parameters, etc .;

2) the used method of solving is not accurate;

3) arithmetic operations and outputting data is rounded.

Errors that correspond these reasons are called:

1) irreversible error;

2) the error of the method;

3) computational error.

For the future, the main thing will not be the nature of the error and the fact of its existence. From this point of view, we will investigate the relationship between the magnitude of the error in the initial conditions and the magnitude of the error in solving the inverse problem and consider a method for studying the areas of equivalent solutions.

\subsection{Three-layer model}

As a geoelectric model of the medium we will consider a three-layer model (Fig. 1).

This model consists of a well (specific resistivity (SR) of mud $-\rho_{W}$ ), invaded zone (or «zone»; SR of zone $-\rho_{Z}$ ) and uninvaded zone (or «layer»; SR of layer $-\rho_{B}$ ).

This model is simplified, but adequately describes the most relevant reservoirs inherent in the conditions of the Dnipro-Donetsk depth (including complex, thin-layer and anisotropic reservoirs, residual oil saturation collectors, abnormally low resistance reservoirs, faulty collectors, etc.).

To determine the values of the reservoir parameters, we consider the following depending on the type of fluid saturation (Table 1).

For simplicity, we will assume from the beginning that the layer has infinite thickness. The case of studying layers of finite thickness requires consideration of the socalled boundary effects [2-3].

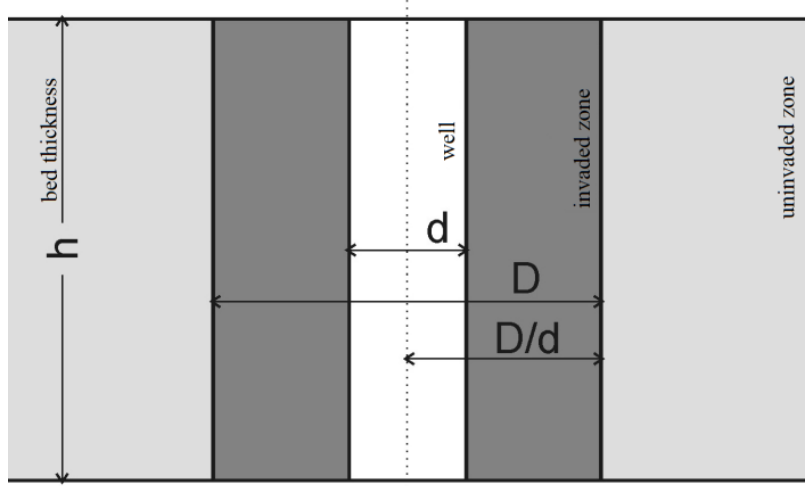

Fig. 1. Three-layer formation model

Table 1. Typical parameters of the layers.

\begin{tabular}{|l|c|c|c|}
\hline Saturation type & $\begin{array}{c}\rho_{B}, \\
\text { Ohm·m }\end{array}$ & $\begin{array}{c}\rho_{Z}, \\
\text { Ohm·m }\end{array}$ & $D / d$ \\
\hline water-saturated & 4,5 & 20 & 5 \\
\hline oil-saturated & 8,5 & 30 & 4 \\
\hline gas-saturated & 50 & 30 & 5 \\
\hline
\end{tabular}

\subsection{Array induction tool}

Our geoelectric model is described by several unknown parameters (for the three-layer infinite model - three). To find them, we need to have at least three known values of measured conductivity or resistance in front of each layer.

Existing and widely used induction logging equipment in the world provides such an opportunity. Such equipment consists of four (seven) probes of lowfrequency induction logging (IL) - 4IK (7IK). The lengths of the sondes are $0.5,0.85,1.26,2.05$ meters (for the 7IK three more sondes of lengths $0.15,0.25,0.35$ meters are added).

The given methods of research of connection of data of direct measurement with unknown values of parameters of model of the investigated layers are applied without restriction of generality and for other multiprobe systems of electrometry. Such equipment consists of $\mathrm{BKZ}$, lateral logging tool (BK) and low-frequency induction logging tool (AIK) and gives us for each layer (measuring point) even 9 measured values that are not linearly dependent. These are six values measured by the $\mathrm{BKZ}$ complex, one value measured by the BK, two values (active and reactive) measured by the AIK.

\section{Solution of the inverse problem in the presence of an error}

\subsection{The magnitude of the equipment error}

The simplest way that can be chosen to study the effect of error in the boundary conditions of the inverse problem on its final result is to find the range of possible solutions that correspond to the range of possible values of the 
boundary conditions. That is the purpose of the study will not be the cause of the error, but how its

magnitude affects the error magnitude of solving the inverse problem.

Before that, let us recall two definitions. A correctly posed (well-difined) problem is a problem that satisfies the following three requirements:

- the problem has a solution (requirement of existence);

- the existing solution is unique (requirement of unity);

- the existing and unique solution continuously depends on the input data (continuity condition).

Unstable problem is a problem for which a small error in the initial data can lead to a much larger error in the solution.

Let us now investigate the mapping of the range of admissible values of each measurement vector into the space of the vectors of the geoelectric section model, using the values of the errors that correspond to what is really possible.

One of the possible ways to determine the magnitude of the error is:

- for BKZ (not more than) in \% $(\tilde{\rho}-\mathrm{AR})$ :

$$
\varepsilon_{B K Z}= \pm\left(2,5+0,004\left(\frac{5000}{\widetilde{\rho}}-1\right)\right)
$$

- for IL (not more than) in $\mathrm{mSm} / \mathrm{m}(\tilde{\sigma}-\mathrm{AC})$ :

$$
\varepsilon_{I L}=0,03 \tilde{\sigma} \pm 1
$$

- for BK (not more than) 5\%.

\subsection{Algorithm for establishing areas of equivalent solutions}

We will demonstrate "the simplest way" on an example of logging by a 4IK complex in two wells.

The error will be set in two ways:

- the measurement of each probe has an error within a given interval, i.e. is not a number but a confidence interval:

$$
\left(1-\frac{\varepsilon}{100}\right) \tilde{\rho}<\tilde{\rho}<\left(1+\frac{\varepsilon}{100}\right) \tilde{\rho} ;
$$

- the resistance of the mud is determined with some error, i.e. $\rho_{W}$ can take any value from the range:

$$
(1-\delta) \rho_{W}<\rho_{W}<(1+\delta) \rho_{W} .
$$

The second type was chosen to study the stability of the solution from well parameters. Consider the solution of the inverse problem for the already mentioned wells: Vatynska (Fig. 2) and Eganska (Fig. 3).

The error values were set as follows: $\varepsilon=10 \%$ (Fig. 2.a, 3.a), $\varepsilon=20 \%$ (Fig. 2.b, 3.b).

\subsection{The inverse problem solving method without error in the initial conditions}

The effectiveness of the inverse problem solving method is determined:
- by the choice of method for determining the measurement data of the sondes for the selected parameters of the environment;

- by choosing the parameter "proximity" of the calculated probe readings and real;

- by the method of selecting model parameters for the selected parameter "proximity".

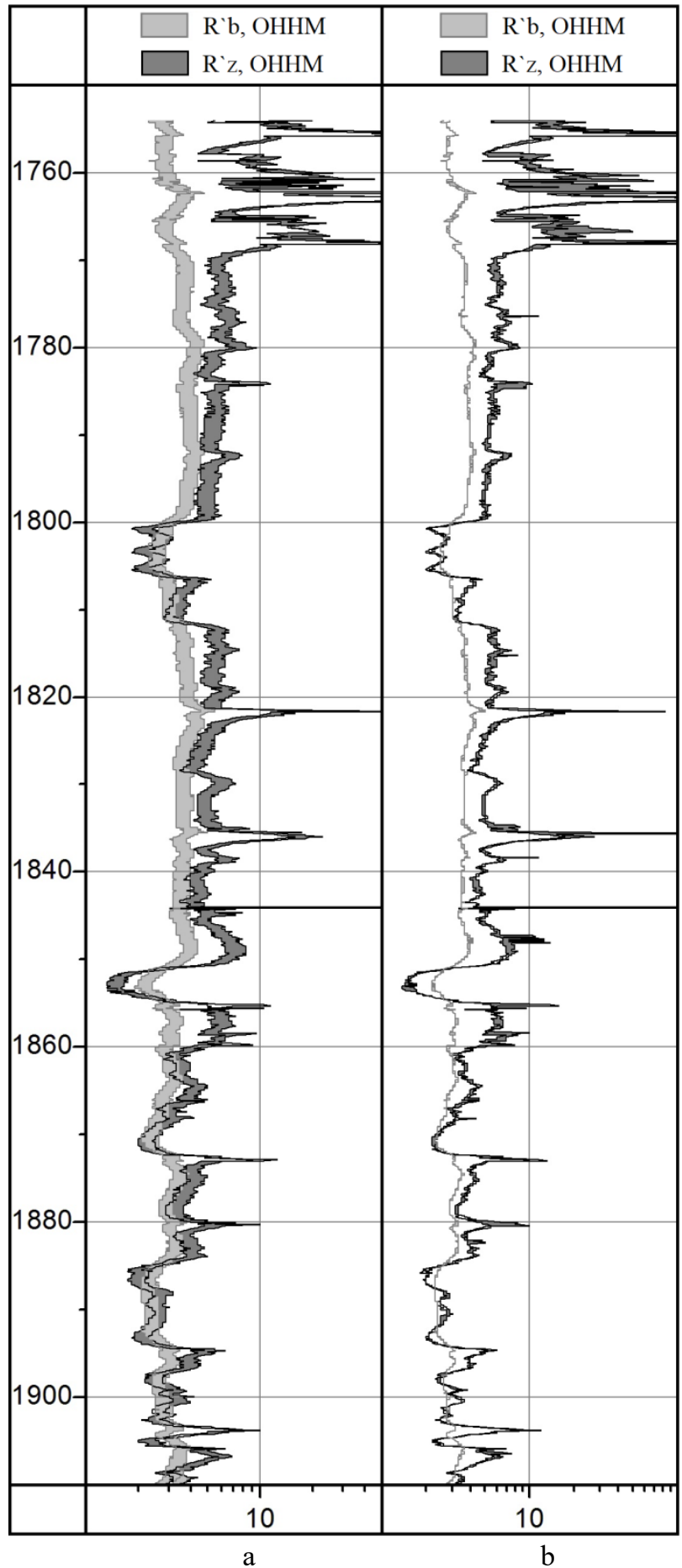

Fig. 2. Well «Vatynska» $\left(\rho_{W}=1.6 \mathrm{Ohm} \cdot \mathrm{m}\right)$. The result of solving the inverse problem

These questions can be paraphrased accordingly as:

- choice of the method of solving the direct problem (finite differences, finite elements, integral currents, semianalytical solution, etc.); 
- the type of functional that will be minimized when solving the inverse problem (previously this item looked like "choosing the visually closest palette");

- method of iterative process of solving the inverse problem.

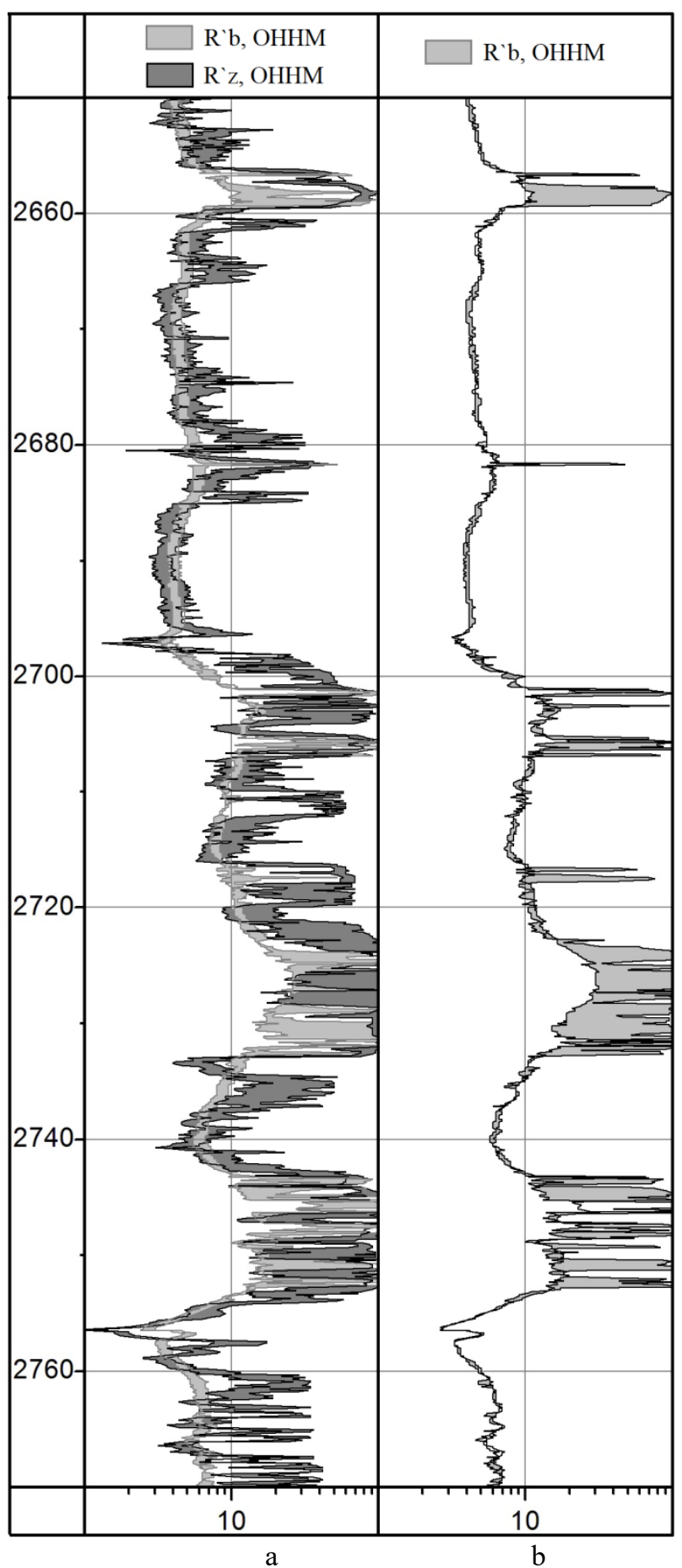

Fig. 3. Well «Eganska» $\left(\rho_{W}=0.34 \mathrm{Ohm} \cdot \mathrm{m}\right)$. The result of solving the inverse problem

We will not consider the first and third issues, assuming that they are resolved.

As a criterion for the proximity of the found solution with the desired true value, we can consider the minimization of the functional:

$$
F\left(\rho_{1}^{T}, \ldots, \rho_{n}^{T}\right)=\frac{1}{n} \sqrt{\sum_{i=1}^{n}\left(\frac{\rho_{i}^{T}-\rho_{i}^{P}}{\rho_{i}^{T}}\right)^{2}}
$$

where is $n$ - the number of equipment sondes; $\rho_{i}^{T-}$ calculated values of AR for the model under consideration; $\rho_{i}^{P}$ - actually obtained values of AR.

There are also some variations of the functional record, which will be minimized in the process of solving the inverse problem. For example, in the form:

$$
F\left(\rho_{1}^{T}, \ldots, \rho_{n}^{T}\right)=\frac{1}{n} \sqrt{\sum_{i=1}^{n}\left(\frac{\rho_{i}^{T}-\rho_{i}^{P}}{\delta_{i} \rho_{i}^{T}}\right)^{2}},
$$

where $\delta_{i}$ - the relative error of the $i$ probe.

Or:

$$
F\left(\rho_{1}^{T}, \ldots, \rho_{n}^{T}\right)=\frac{1}{n} \sqrt{\sum_{i=1}^{n}\left(\frac{\rho_{i}^{T}-\rho_{i}^{P}}{\delta_{i} \rho_{i}^{T}+\chi_{i}}\right)^{2}},
$$

where $\chi_{i}$ - the absolute error of the $i$ probe.

We will consider the functionality of the form:

$$
F\left(\rho_{1}^{T}, \ldots, \rho_{n}^{T}\right)=\sqrt{\sum_{i=1}^{n} K_{i}\left(\frac{\rho_{i}^{T}-\rho_{i}^{P}}{\rho_{i}^{T}}\right)^{2}},
$$

where $K_{i}$ - weight coefficients of each sonde of the complex, which can be changed by the interpreter.

Several studies have been devoted to the choice of different values of weights.

It is clear that the change in weights will significantly affect the size of the area of equivalent solutions, because it can reduce the impact of sondes that have a larger measurement error and increase the impact of sondes that have a smaller measurement error, for example.

Further research will be devoted to this issue. In this study, without loss of generality, we will assume that:

$$
\forall i: K_{i}=1 \text {. }
$$

\subsection{Examples of the inverse problem solving taking into account the error in the initial conditions}

To demonstrate the method, we take the real well material and assume that the result is obtained with an error (Fig. 2.a, Fig.3.a $-\varepsilon=20 \%$; Fig. 2.b, Fig. $3 . \mathrm{b}-\delta=0.2$ ). For such values of possible initial intervals we will solve the inverse problem (we will define $\rho_{B}, \rho_{Z}$ that are designated as R'b, R'z in Fig. 2,3).

Note that in Fig. 3.b shows the results only for the AR of layer, because the intervals of possible values of the zone are frankly chaotic and do not carry any information, resembling a random number generator and therefore not given. This chaotic nature is evidence of a typical example of an unstable solution, when for each specific value of the measurement data we have a specific solution value, but a small change in the measurement data corresponds to a large (orders of magnitude larger) change in the solution value of the inverse problem. This is also an 
example the way of how a solution can satisfy a condition of continuity but not be stable.

Based on the results obtained, the following conclusions were made.

For a well filled with clay drilling mud (Fig. 2):

- the inverse problem of the 4IL complex within the values of the model parameters is stable relatively to the measurement error (the range of possible values of the model parameters is almost proportional to the range of possible measurement values (Fig. 2.a));

- the inverse problem for the 4IL complex within the values of the model parameters up to $10 \mathrm{mSm} / \mathrm{m}$ is stable relatively to the change of $\rho_{W}$ (the range of possible values of model parameters is almost proportional to the range of possible drilling fluid values (Fig. 2.b));

- the inverse problem for the 4IL complex within the values the model parameters more than $10 \mathrm{mSm} / \mathrm{m}$ satisfies the condition of continuity, but is not relatively to the change of $\rho_{W}$ (the range of possible values of model parameters is much larger than the range of possible $\rho_{W}$ values (Fig. 2.b));

- values of $\mathrm{R}^{`} \mathrm{z}$ are more "sensitive" to change of parameters of a well, than values of $R^{\prime} b$.

For a well filled with saline drilling mud (Fig. 3):

- the inverse problem of the 4IL complex within the values of the model parameters up to $10 \mathrm{mSm} / \mathrm{m}$ is stable relatively to the measurement error (the range of possible values of the model parameters is almost proportional to range of possible measurement values (Fig. 3.a));

- the inverse problem of the 4IL complex within the values of model parameters more than $10 \mathrm{mSm} / \mathrm{m}$ satisfies the condition of continuity, but is not stable relatively to measurement error (the range of possible values of model parameters is much larger than the range of possible values of measurements (Fig. 3.a);

- the inverse problem of the 4IL complex is not stable relatively to the change of $\rho_{W}$ (the range of possible values of one of the parameters of the model (namely $\mathrm{R}^{\prime} \mathrm{z}$ ) is much larger than the interval of possible values of $\rho_{W}$;

- the parameter $\mathrm{R}^{\prime} \mathrm{b}$ has both a stable region of definition (up to $10 \mathrm{mSm} / \mathrm{m}$ ) and an unstable region of definition (more than $10 \mathrm{mSm} / \mathrm{m}$ ), as can be seen in Fig. 3.b.

There are many similar examples of wells and complexes, but the main one is the fact that, in principle, there are areas of unstable solutions in wells.

That is, by setting specific values of the AR, we will, of course, get a specific value of the solution, but it may be unstable. It is clear that such a solution cannot be used while GWR

Alternatively, in further interpretation, it will lead to erroneous conclusions regarding the determination of well performance characteristics.

So, we come to the conclusion that it is not enough to have a way to solve the inverse problem on its own. We also need to have a method that will allow to determine the areas of stability of the solutions of the inverse problem for each section model and each electrometry complex.

\section{Spatial resolution characteristics of solving the inverse problem}

Consider the space of the parameters $\mathbf{P}$ of the studied objects $\mathbf{p}$ and the space $\mathbf{G}$ of possible values $\mathbf{g}$ of measurement by the well-logging complex. In order for the problem to have a solution, we will require that the number of independent measurements be greater or equal to the number of required parameters of the model. There is a unique mapping: $\mathbf{P} \rightarrow \mathbf{G}$ (we will denote the corresponding mapping function $G$ ). Consider the features of the inverse mapping (we will denote the corresponding function $G^{-1}$ ), which in the case of mapping one element will be considered unambiguous. If the mapping object is not one element $\mathbf{g}$, but an area $\mathbf{g}+$ $\Delta \mathbf{g}$ where $\Delta \mathbf{g}$ takes any values within the allowable error, then the image of such a mapping will also be some. Consider the following mapping:

$$
\mathbf{p}+\Delta \mathbf{p}=G^{-1}(\mathbf{g}+\Delta \mathbf{g})
$$

Note that since the inverse problem is nonlinear, the value depends on both the model itself and the measurement error: $\Delta \mathbf{p}=\Delta \mathbf{p}(\mathbf{p}, \Delta \mathbf{g})$. The measurement error also generally depends on the model of the environment: $\Delta \mathbf{g}=\Delta \mathbf{g}(\mathbf{p})$.

Such a complex dependence does not allow to introduce a general simple concept and definition of the spatial resolution of the equipment not only for the whole range of parameters of all possible current models of sections, but even for a set of several separate models and requires the study of quantitative dependence (4) for each model.

Accordingly, we can talk about the characteristics of the spatial resolution of specific equipment only for a specific model of the section: even with a slight change in the parameters of the model, the characteristics can change significantly. This is exactly what we observed in the previous section.

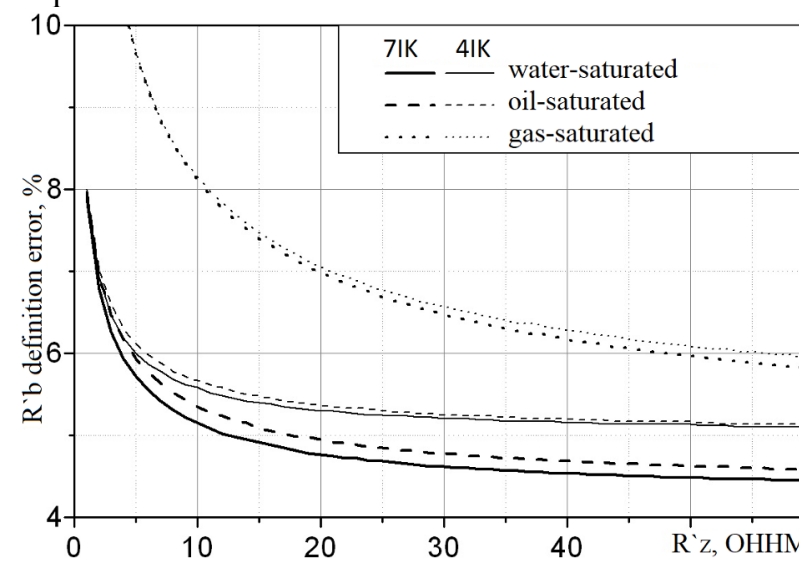

Fig. 4. Dependence of the error in determining the $\rho_{B}$ on the $\rho_{Z}$

Therefore, the analysis of such characteristics should be performed for a separately selected model.

For each such selected model we will perform the following steps:

1. Set its parameters - determine the vector of model parameters $\mathbf{p}$ (we will use table 1). 
2. Solve a direct problem for $\mathbf{p}$ - determining the vector of measurements $\mathbf{g}=G(\mathbf{p})$.

3 . Solve the inverse problem for a definite $\mathbf{g}$ - finding an element such that:

$$
\mathbf{p}^{`}=G^{-1}(\mathbf{g})=G^{-1}(G(\mathbf{p})) .
$$

4. Compare $\mathbf{p}$ ' and $\mathbf{p}$ - determine the accuracy of solving the inverse problem.

If it does $\mathbf{p}$ ' not differ from $\mathbf{p}$ (within the allowable, arbitrarily small, predetermined error), we will assume that:

$$
\mathbf{p}^{`} \equiv \mathbf{p}
$$

Execution (5) will mean that the obtained characteristic of the spatial resolution is correct and does not depend on the method of solving the inverse problem.

5. Solving the inverse problem for the area $\mathbf{g}+\Delta \mathbf{g}-$ finding the set of possible models $\mathbf{p}+\Delta \mathbf{p}$ that correspond $\mathbf{g}+\Delta \mathbf{g}$ (determination of the error $\Delta \mathbf{p}$ depending on the given value of the error $\Delta \mathbf{g}$ ).

\section{Results}

We will demonstrate this connection between the registration error and the error of possible determination of the required parameters.

The error will be set separately for each sonde. To qualitatively explain the expected results, it is enough to use the approximate Doll's theory and record the AC measured by each sonde, ignoring the signal from the well in the form:

$$
\sigma^{i}=\frac{g_{Z}^{i}}{\rho_{Z}}+\frac{g_{B}^{i}}{\rho_{B}}
$$

where $\sigma^{i}$ - the apparent conductivity of the $i$ th probe; $g_{Z}^{i}$, $g_{B}^{i}$ - geometric factors of the invaded zone and the layer.

It is obvious that the relative accuracy of determining the SR of the layer and the invaded zone is

related to the relationship between the first and second terms in (6).

Yes, when:

$$
\frac{g_{Z}^{i}}{\rho_{Z}}<<\frac{g_{B}^{i}}{\rho_{B}}
$$

the parameters of the invaded zone are determined with a much larger error at than the parameters of the layer at $\rho_{Z}=$ const .

In addition, condition (7) is fulfilled particularly strictly with increasing penetration, when, in addition, condition (6) is amplified even more. The error in determining the parameters of the near zone is improving with decreasing penetration, because the condition significantly weakens condition (7). But, among other things, this is confirmed by direct numerical simulation of the spatial resolution characteristics.

Thus, Fig. 4 shows the dependence of the accuracy of determining the SR of the layer from the SR of the zone, Fig. 5 - the dependence of the accuracy of determining the SR of the layer on the diameter of the zone, Fig. $6-$ the dependence of the accuracy of determining the SR of the zone on the diameter of the last one.

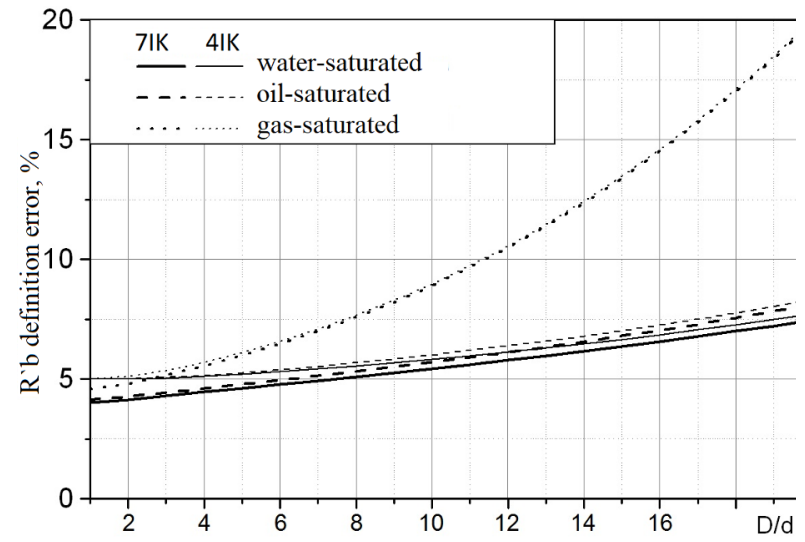

Fig. 5. Dependence of the error in determining the $\rho_{Z}$ on the diameter of the zone

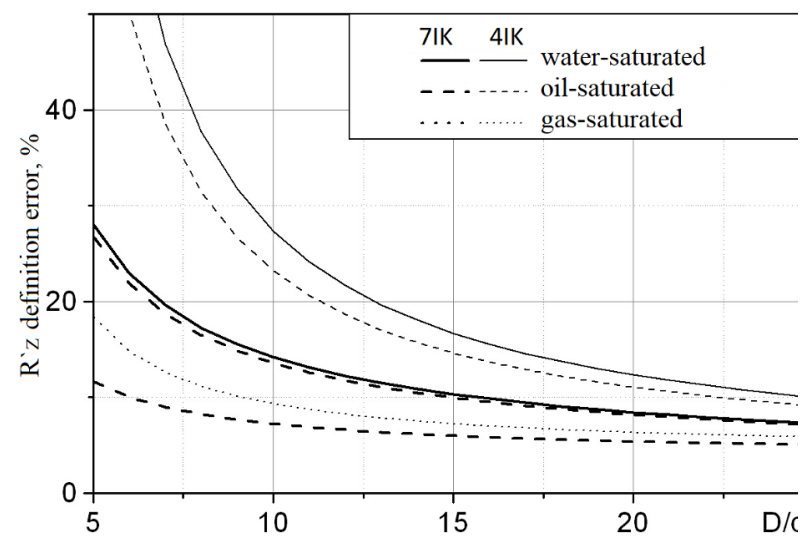

Fig. 6. Dependence of the error in determining the $\rho_{Z}$ on the diameter of the zone

\section{Conclusions}

These results lead to the following conclusions:

- Before the practical application of any method of solving the inverse problem, it is advisable to explore the areas of stability of its solutions, which will allow them to be used in the future without losing useful information.

- In order to be able to effectively further work with the obtained results, it is also advisable to explore the areas of equivalent models that correspond to the real error of logging and its geophysical conditions.

- The given method of research of spatial resolution of the solution of the inverse problem of electrometry of oil and gas wells allows to investigate effectively areas of stability of its decisions and areas of equivalent models corresponding to a real error of logging and its geophysical conditions.

The question of why use (2) is more adequate than use (1) will be covered later.

\section{References}

1. B. Anderson, Modeling and inversion methods for the interpretation of resistivity logging tool response 


\section{(Delft: DUP Science, 2001)}

2. M. Myrontsov, O. Karpenko, O. Trofymchuk, V. Okhariev, Y. Anpilova, Increasing vertical resolution in electrometry of oil and gas wells. Systems, decision and control in energy II. Studies in systems, decision and control (Springer, Cham, 2021), (to be published)

3. M.L. Myrontsov, O.M. Karpenko, O.M. Trofymchuk, V.O. Okhariev, Examples of determination of spatial and geoelectric parameters of productive beds of deposits of the Dnipro-Donetsk depth. XIV International Scientific Conference "Monitoring of Geological Processes and Ecological Condition of the Environment", Extended Abstracts (2020)

4. O. Karpenko, M. Myrontsov, I. Karpenko, V. Sobol, Detection conditions of gas-saturated layers by the result of complex interpretation of non-electrical well logging data. XIV International Scientific Conference "Monitoring of Geological Processes and Ecological Condition of the Environment", Extended Abstracts (2020)

5. O. Trofymchuk, Y. Yakovliev, Y. Anpilova, M. Myrontsov, V. Okhariev, Ecological situation of post-mining regions in Ukraine. Systems, decision and control in energy II. Studies in systems, decision and control (Springer, Cham, 2021), (to be published)

6. O. Trofymchuk, Y. Yakovliev, V. Klymenko, Y. Anpilova, Geomodeling and monitoring of pollution of waters and soils by the earth remote sensing. International Multidisciplinary Scientific GeoConference - SGEM, 19, 1.4 (2019)

7. O. Trofymchuk, O. Kolodyazhnyy, E. Yakovlev, Hazardous activation of landslides within Western Carpathian Region (Ukraine). Landslide Science for a Safer Geoenvironment (Springer, Cham, 2014)

8. O. Korchenko,V. Pohrebennyk, D. Kreta, V. Klymenko, Y. Anpilova. GIS and remote sensing as important tools for assessment of environmental pollution. 19th International Multidisciplinary Scientific GeoConference SGEM 2019, Extended Abstracts, 19, 2.1 (2019)

9. O. Trofymchuk, Y.Anpilova, Y. Yakovliev, I. Zinkiv, Ground Deformation Mapping of Solotvyno Mine Area Using Radar Data and GIS. 19th International Conference Geoinformatics: Theoretical and Applied Aspects, Extended Abstracts (2020)

10. Y. Anpilova, Y. Yakovliev, I. Drozdovych, Landscape and Geological Factors of Water and Ecological Conditions Technogenesis of Donbas at the Post-Mining Stage. 19th International Conference Geoinformatics: Theoretical and Applied Aspects, Extended Abstracts (2020)
11. V. Lukianova, O. Trofymchuk, Y. Anpilova, Environmental safety of motor transport enterprises within the urban areas. Journal of Ecological Engineering. 21, 4 (2020)

12. O. Trofymchuk, V. Klymenko, Y. Anpilova, N. Sheviakina, S. Zagorodnia, The aspects of using GIS in monitoring of environmental components 20th International Multidisciplinary Scientific GeoConference SGEM. (2020)

13. O.T. Azimov, I.V. Kuraeva, O.M. Trofymchuk, S.P. Karmazynenko, Ye.M. Dorofey, YuYu. Voytyuk, Estimation of the heavy metal pollution for the soils and different environmental objects within the solid domestic waste landfills. Conference Proceedings, 18th International Conference on Geoinformatics Theoretical and Applied Aspects (2019)

14. L. Shkitsa, T. Yatsyshyn, M. Lyakh, O. Sydorenko, Innovative approaches to the formation of environmental safety at the objects of oil and gas production. IOP Conf. Ser.: Mater. Sci. Eng. 749, 012009 (2020)

15. T. Yatsyshyn, N. Glibovytska, L. Skitsa, M. Liakh, S. Kachala, Biotechnogenic System Formed by LongTerm Impact of Oil Extraction Objects, in Studies in Systems, Decision and Control Systems, vol. 298, ed. by V. Babak, V. Isaienko, A. Zaporozhets (Springer, Cham, 2020)

16. L. Skitsa, T. Yatsyshyn, M. Liakh, O. Sydorenko, Ways to improve safety of a pumping-circulatory system of a drilling rig. Mining of Mineral Deposits 12(3), 71-79 (2018)

17. L. Shkitsa, T. Yatsyshyn, M. Lyakh, O. Sydorenko, Means of atmospheric air pollution reduction during drilling wells. IOP Conf. Ser.: Mater. Sci. Eng. 144, 012009 (2016)

18. N. Pobihun, Y. Korobeinykova, O. Pobihun, I. Iuras, Ecological and monitoring studies of oil production territories and possibility of their use in recreation, in Proceedings of the XIII International Scientific Conference "Monitoring of Geological Processes and Ecological Condition of the Environment" (2019)

19. S. Kis, L. Mosora, Y. Mosora, O. Yatsiuk, G. Malynovska, S. Pobihun, Personnel Certification as a Necessary Condition for Enterprise' Staff Development, Management Systems in Production Engineering 28, 2 (2020)

20. O. Mandryk, N. Moskalchuk L. Arkhypova, M. Prykhodk, O. Pobigun. Prospects of environmentally safe use of renewable energy sources in the sustainable tourism development of the Carpathian region of Ukraine. E3S Web Conf. 166, 04005 (2020)

21. O.M. Mandryk, N.R. Moskalchuk, L.M. Arkhypova, M.M. Pryhodko, O.V. Pobigun, Research quantitative indicators of the potential of solar energy 
in the Carpathian region of Ukraine. IOP Conf. Ser.: Mater. Sci. Eng. 749, 012033 (2020)

22. O.M. Mandryk, L.M. Arkhypova, O.V. Pobigun, O.R. Maniuk, Renewable energy sources for sustainable tourism in the Carpathian region. IOP Conf. Ser.: Mater. Sci. Eng. 144, 012007 (2016)

23. O. Savko, I. Melnychuk, I. Hobyr, N. Havadzyn, Evaluation of the environmental taxation effectiveness in the field of oil and gas production. Procedia Environ. Sci. Eng. Manag. 6, 4 (2019)

24. A. Zaporozhets, Overview of Quadrocopters for Energy and Ecological Monitoring, in Studies in Systems, Decision and Control Systems, vol. 298, ed. by V. Babak, V. Isaienko, A. Zaporozhets (Springer, Cham, 2020)

25. A.O. Zaporozhets, Research of the Process of Fuel Combustion in Boilers, in Studies in Systems, Decision and Control Systems, vol. 287 (Springer, Cham, 2020)

26. A.O. Zaporozhets, Methods and Means for the Control of the Fuel Combustion, in Studies in Systems, Decision and Control Systems, vol. 287 (Springer, Cham, 2020)

27. A. Zaporozhets, Analysis of control system of fuel combustion in boilers with oxygen sensor. Periodica Polytechnica Mechanical Engineering 63, 4 (2019)

28. A. Iatsyshyn, A. Iatsyshyn, V. Artemchuk, I. Kameneva, V. Kovach, O. Popov, Software tools for tasks of sustainable development of environmental problems: peculiarities of programming and implementation in the specialists' preparation. E3S Web Conf. 166, 01001 (2020)

29. Y. Kyrylenko, I. Kameneva, O. Popov, A. Iatsyshyn, V. Artemchuk, V. Kovach, Source Term Modelling for Event with Liquid Radioactive Materials Spill, in Studies in Systems, Decision and Control Systems, 298 (Springer, Cham, 2020)

30. A. Iatsyshyn, A. Iatsyshyn, V. Kovach, I. Zinovieva, V. Artemchuk, O. Popov, O. Cholyshkina, O. Radchenko, O. Radchenko, A. Turevych, Application of Open and Specialized Geoinformation Systems for Computer Modelling Studying by Students and PhD Students. CEUR Workshop Proceedings 2732 (2020)

31. A.V. Iatsyshyn, V.O. Kovach, V.O. Lyubchak, Y.O. Zuban, A.G. Piven, O.M. Sokolyuk, A.V. Iatsyshyn, O.O. Popov, V.O. Artemchuk, M.P. Shyshkina, Application of augmented reality technologies for education projects preparation. CEUR Workshop Proceedings 2643 (2020)

32. O. Trofymchuk, M. Myrontsov, V. Okhariev, Y. Anpilova, V. Trysnyuk, Transdisciplinary analytical system for support the environmental researches. Systems, decision and control in energy II. Studies in systems, decision and control (Springer, Cham, 2021), (to be published)

33. O.M. Trofymchuk, V.M. Trysnyuk, V.O. Okhariev, Environmental security management of geosystems. 18th International Conference on Geoinformatics Theoretical and Applied Aspects, Extended Abstracts (2019)

34. A. Greben, O. Trofymchuk, V. Trysnyuk, G. Krasovskiy, Interpretation of remote sensing data for ecological tasks. 2020 IEEE UkrainianMicrowave Week (UkrMW): 10th International Kharkiv Symposium on Physics and Engineering of Microwaves, Millimeter and Submillimeter Waves (21-25 September, Kharkiv, Ukraine), 3 (2020)

35. V.M. Trysnyuk, K.V. Smetanin., T.V. Trysnyuk, Y.V. Holowan, O.L. Kashchishin, K.O. Radlowska, The improvement of the system of ecological monitoring of the environment through the application of remotely piloted aircraft systems. XIII International Scientific Conference "Monitoring of Geological Processes and Ecological Condition of the Environment", Extended Abstracts. (2019)

36. V. Trysnyuk, T. Trysnyuk, V. Okhariev, V. Shumeiko, A. Nikitin, Cartographic model of Dniester river basic probable floding. Series D, Geology and Environmental Engineering. D. 22, 1 (2018)

37. V. Trysnyuk, O. Demydenko, K. Smetanin., A. Zozulia, Improvement of the complex evaluation method of vital activity risks. 19th International Conference Geoinformatics - Theoretical and Applied Aspects, Extended Abstracts. (2020)

38. V. Trysnyuk, V. Prystupa, T. Trysnyuk, V. Vasylenko, A. Kurylo, Comprehensive environmental monitoring based on aerospace and ground research data. 19th International Conference Geoinformatics - Theoretical and Applied Aspects, Extended Abstracts. (2020)

39. V. Trysnyuk, V. Okhariev, Y. Anpilova, T. Trysnyuk, Y. Nagorny, Environmental monitoring based on aerospace and terrestrial researches. XIV International Scientific Conference "Monitoring of Geological Processes and Ecological Condition of the Environment", Extended Abstracts. (2020)

40. V. Romanyuk, V. Trysnyuk, M. Pidhorodetskyi, A. Nikitin, The mathematical formulation of the scientific problem of liquidation of consequences of natural and man-caused catastrophes on the territory of Ukraine. Polish journal of science. 1, 31 (2020)

41. O.M. Trofymchuk, Yu.I. Kaliukh, V.A. Dunin, Y.A. Berchun, On the Possibility of Multi-Wavelength Identification of Defects in Piles. Cybernetics and Systems Analysis, 54 (2018)

42. I. Kaliukh, V. Senatorov, N. Marienkov, O. Trofymchuk, K. Silchenko, T. Kalyukh, 
Arrangement of deep foundation pit in restricted conditions of city build-up in landslide territory with considering of seismic loads of 8 points. Geotechnical Engineering for Infrastructure and Development - Proceedings of the XVI European Conference on Soil Mechanics and Geotechnical Engineering (2015)

43. R. Baum, T. Miyagi, S. Lee, O. Trofymchuk, Introduction: Hazard Mapping. Landslide Science for a Safer Geoenvironment (Springer, Cham, 2014)

44. O. Trofymchuk, Y. Kalyukh, H. Hlebchuk, Mathematical and GIS-modeling of landslides in Kharkiv region of Ukraine. Landslide Science and Practice: Spatial Analysis and Modelling (Springer, Berlin, 2013)

45. A.M. Gomilko, N.S. Gorodetskaya, A.N. Trofimchuk, Harmonic vibrations of a rigid impervious punch on a porous elastic base. International Applied Mechanics 35 (1999)

46. O. Trofymchuk, I. Kaliukh, K. Silchenko, V. Polevetskiy, V. Berchun, T. Kalyukh, Use accelerogram of real earthquakes in the evaluation of the stress-strain state of landslide slopes in seismically active regions of Ukraine. Engineering Geology for Society and Territory - Volume 2 (Springer, Cham, 2015)

47. O. Trofymchuk, Yu. Kalyukh, I. Trofimova, H. Hlebchuk, Modelling of Landslide Hazards in Kharkov Region of Ukraine Using GIS. Landslides: Global Risk Preparedness (Springer, Berlin, Heidelberg, 2013)

48. A.M. Gomilko, A.N. Trofimchuk, Asymptotic Solution of Contact Harmonic Problem for an Impenetrable Stamp on a Poroelastic Base. International Journal of Fluid Mechanics Research, 28, 1-2 (2001)

49. A.N. Trofimchuk, Unsteady Oscillations of a LiquidSaturated Poroelastic Soil Layer. International Journal of Fluid Mechanics Research, 29, 1 (2002)

50. I. Kaliukh, O. Trofymchuk, G. Farenyuk, O. Ivanik, S. Shekhunova, Practical measures fo landslide risk mitigation in the Ukrainian Carpathians. First EAGE Workshop on Assessment of Landslide and Debris Flows Hazards in the Carpathians (2019)

51. A.N. Trofimchuk, V.A. Vasyanin, Simulation of packing, distribution and routing of small-size discrete flows in a multicommodity network. Journal of Automation and Information Sciences, 47, 7 (2015) 